Gut and Liver, Vol. 11, No. 5, September 2017, pp. 667-673

\title{
Advanced Colonic Neoplasia at Follow-up Colonoscopy According to Risk Components and Adenoma Location at Index Colonoscopy: A Retrospective Study of 1,974 Asymptomatic Koreans
}

\author{
Su Jung Baik ${ }^{1}$, Hyojin Park ${ }^{2}$, Jae Jun Park ${ }^{2}$, Hyun Ju Lee ${ }^{1}$, So Young Jo ${ }^{1}$, Yoo Mi Park ${ }^{1}$, and Hye Sun Lee \\ ${ }^{1}$ Healthcare Research Team of Health Promotion Center, ${ }^{2}$ Division of Gastroenterology, Department of Internal Medicine, Gangnam Severance \\ Hospital, Yonsei University College of Medicine, and ${ }^{3}$ Biostatistics Collaboration Unit, Medical Research Center, Yonsei University College of \\ Medicine, Seoul, Korea
}

Background/Aims: We aimed to estimate the cumulative incidence of advanced colonic neoplasia and analyze the risk factors for advanced colonic neoplasia according to risk components and adenoma location at index colonoscopy. Methods: We reviewed 1,974 subjects who underwent a follow-up colonoscopy after a complete screening colonoscopy and the removal of all polyps. We estimated the cumulative incidence of a subsequent advanced neoplasia according to risk groups (normal, low-risk, and high-risk). Risk factors were analyzed by risk components ( $\geq 3$ adenomas, adenoma $\geq 1 \mathrm{~cm}$, and villous-type adenoma) and adenoma location. Results: Overall, 111 advanced neoplasias (5.6\%) were newly diagnosed at the follow-up colonoscopy. The 3-year cumulative incidences of advanced neoplasia were $0.8 \%, 3.1 \%$, and $10.2 \%$ in the normal, low-risk, and high-risk groups, respectively ( $p<0.0001)$, and the 5 -year cumulative incidences were $2.2 \%, 8.6 \%$, and $20.2 \%$, respectively ( $p<0.0001$ ). Age $\geq 60$ years (hazard ratio [HR], 1.78; 95\% confidence interval [Cl], 1.21 to 2.63), right-sided colonic adenoma (HR, 1.74; $95 \% \mathrm{Cl}, 1.13$ to 2.66 ), $\geq 3$ adenomas (HR, 2.00; 95\% Cl, 1.22 to 3.28 ), and adenomas $\geq 1 \mathrm{~cm}$ in size (HR, 2.03; 95\% Cl, 1.20 to 3.44 ) in the index colonoscopy were independent risk factors for subsequent development of advanced neoplasia. Conclusions: Right-sided colonic adenoma, $\geq 3$ adenomas, adenomas $\geq 1 \mathrm{~cm}$, and age $\geq 60$ years at the index colonoscopy were significant risk factors for advanced neoplasia following a complete screening colonoscopy and removal of all polyps. (Gut Liver 2017;11:667-673)

Key Words: Colonic neoplasms; Colonoscopy; Early detection of cancer

\section{INTRODUCTION}

Colorectal cancer (CRC) is a major cause of mortality. ${ }^{1,2}$ It is the second most commonly diagnosed cancer in Korea, after thyroid cancer, ${ }^{3}$ where it accounts for 17\% of newly diagnosed cancers. ${ }^{4}$ Considering that the transition from premalignant to malignant status takes 10 to 15 years, early detection of CRC is crucial. ${ }^{5}$ Colonoscopy is associated with lower CRC mortality rates $^{6,7}$ and is a well-established screening modality, recommended for all individuals $>50$ years old. ${ }^{8}$ Because the prevalence of advanced adenoma and the incidence of CRC increases with age, advanced adenomas, implicated in the etiology of colon cancer, are a significant concern for the average-risk individual.

For the Korean population, one prospective study reported that the 3- and 5-year incidence of advanced adenoma recurrence after polypectomy in high-risk patients was 9.6\% and $12.2 \%$, respectively. ${ }^{9}$ The presence of $\geq 3$ adenomas and an adenoma size $\geq 1 \mathrm{~cm}$ were independent predictors for recurrent advanced colorectal neoplasia. ${ }^{9}$ Two recent retrospective studies reported that age is a significant risk factor for developing colorectal neoplasms after removal of high-risk adenomas, ${ }^{10}$ and that the presence of multiple high-risk findings was associated with an increased risk of advanced neoplasia during surveillance. $^{11}$

The aims of this study were to determine the cumulative incidence of advanced neoplasia at follow-up colonoscopy in subjects who had undergone complete screening colonoscopy

Correspondence to: Hyojin Park

Division of Gastroenterology, Department of Internal Medicine, Gangnam Severance Hospital, Yonsei University College of Medicine, 211 Eonju-ro, Gangnam-gu, Seoul 06273, Korea

Tel: +82-2-2019-3318, Fax: +82-2-3463-3882, E-mail: HJPARK21@yuhs.ac

Received on August 12, 2016. Revised on December 12, 2016. Accepted on February 8, 2017. Published online July 28,2017 pISSN 1976-2283 eISSN 2005-1212 https://doi.org/10.5009/gnl16402

@) This is an Open Access article distributed under the terms of the Creative Commons Attribution Non-Commercial License (http://creativecommons.org/licenses/by-nc/4.0) which permits unrestricted non-commercial use, distribution, and reproduction in any medium, provided the original work is properly cited. 
and removal of all polyps, and to identify the risk factors for advanced neoplasia according to risk components and adenoma location at index colonoscopy in asymptomatic subjects. We analyzed subsequent advanced neoplasia by risk components $(\geq 3$ adenomas, adenoma size $\geq 1 \mathrm{~cm}$, and villous-type adenoma) and adenoma location at index colonoscopy.

\section{MATERIALS AND METHODS}

\section{Study subjects}

A total of 11,930 subjects underwent cancer screening colonoscopy at the Health Promotion Center of Gangnam Severance Hospital between July 2007 and January 2012. Of these, we excluded those with baseline CRC; nonneoplastic polyps, such as hyperplastic or inflammatory polyps; those whose colonoscopy was incomplete; and subjects who did not undergo follow-up colonoscopy. Thus, we retrospectively analyzed 1,974 outpatients. For 1,588 of the 1,974 subjects (80.4\%), the index colonoscopy was their first colonoscopy, whereas 225 subjects (11.4\%) had undergone colonoscopy previously, and 161 (8.2\%) had an unknown colonoscopy history. All 225 subjects with previous colonoscopy reported no significant findings (such as colon cancer) or colonic surgery. Polyps and adenomas detected during colonoscopy were removed by standard biopsy using forceps or by polypectomy. All colonoscopies were performed by six board-certified endoscopists, each of whom had performed $>3,000$ colonoscopies and had an adenoma detection rate of $>25 \%$ for routine procedures. ${ }^{8}$

Subjects were grouped according to risk, based on the index colonoscopy findings, as follows: a high-risk group, subjects with advanced adenoma or $\geq 3$ adenomas; a low-risk group, those with 1 to 2 adenomas $<1 \mathrm{~cm}$ in size; and a normal group, subjects with no colonic polyps (of any kind) at index colonoscopy. The cumulative incidence of advanced neoplasia at follow-up colonoscopy was determined stratified by risk group. The study was approved by the Yonsei University Gangnam Severance Hospital's Institutional Review Board (approval number: 3-2015-0040).

\section{Variables and definitions}

Colonic neoplasias were histopathologically confirmed as being either adenomas or adenocarcinomas. Advanced adenoma was defined as a lesion $\geq 1 \mathrm{~cm}$ in diameter, a lesion with villous or tubulovillous histologic characteristics, or a lesion with high-grade dysplasia. ${ }^{12}$ Advanced neoplasia was defined as advanced adenoma or adenocarcinoma. Synchronous adenomas were evaluated and the size of the largest one was used in the analysis. The size of the adenomas was estimated using biopsy forceps. Right-sided colonic adenomas were defined as those occurring in the portion of the colon proximal to the splenic

Table 1. Comparison of Baseline Characteristics among Subjects Who Underwent a Follow-up Colonoscopy

\begin{tabular}{|c|c|c|c|c|c|}
\hline Characteristic & $\begin{array}{l}\text { Overall } \\
(\mathrm{n}=1,974)\end{array}$ & $\begin{array}{l}\text { Normal group } \\
(n=574)\end{array}$ & $\begin{array}{l}\text { Low-risk group } \\
\qquad(\mathrm{n}=1,050)\end{array}$ & $\begin{array}{l}\text { High-risk group } \\
\quad(\mathrm{n}=350)\end{array}$ & p-value \\
\hline Age, yr & $55.7 \pm 7.1$ & $53.3 \pm 6.4$ & $56.1 \pm 6.8$ & $58.3 \pm 7.6$ & $<0.0001$ \\
\hline Male sex & $1,423(72.1)$ & $379(66.0)$ & $768(73.1)$ & 276 (78.9) & $<0.0001$ \\
\hline Follow-up duration, mo & $41.8 \pm 21.7$ & $49.5 \pm 23.7$ & $38.9 \pm 20.1$ & $37.7 \pm 19.6$ & $<0.0001$ \\
\hline 2 Or more adenomas & $572(29.0)$ & - & $279(26.6)$ & $293(83.7)$ & $<0.0001$ \\
\hline Advanced adenoma & $201(10.2)$ & - & - & $201(57.4)$ & \\
\hline Age group, yr & & & & & $<0.0001$ \\
\hline $40-59$ & $1,438(72.9)$ & 475 (82.8) & $753(71.7)$ & $210(60.0)$ & \\
\hline $60-69$ & $439(22.2)$ & $86(15.0)$ & $241(23.0)$ & $112(32.0)$ & \\
\hline$\geq 70$ & $97(4.9)$ & $13(2.2)$ & $56(5.3)$ & $28(8.0)$ & \\
\hline Adenoma location & & & & & $<0.0001$ \\
\hline Right-sided only & $542(27.5)$ & - & $475(45.2)$ & $67(19.1)$ & \\
\hline Left-sided only & $549(27.8)$ & - & $466(44.4)$ & $83(23.7)$ & \\
\hline Both RT and LT & 309 (15.7) & - & $109(10.4)$ & $200(57.2)$ & \\
\hline Villous component & $69(3.5)$ & - & - & 69 (19.7) & \\
\hline Adenoma $\geq 1 \mathrm{~cm}$ & $182(9.2)$ & - & - & $182(52.0)$ & \\
\hline$\geq 3$ Adenomas & $239(12.1)$ & - & - & $239(68.3)$ & \\
\hline Current smoking & $320(16.2)$ & $71(12.4)$ & $175(16.7)$ & $74(21.1)$ & 0.002 \\
\hline Family history of colorectal cancer & $79(4.0)$ & $20(3.5)$ & $46(4.4)$ & $13(3.7)$ & 0.648 \\
\hline Withdrawal time, min & $7.9 \pm 5.0$ & $4.6 \pm 2.4$ & $8.3 \pm 3.6$ & $12.2 \pm 5.8$ & $<0.001$ \\
\hline
\end{tabular}

Data are presented as mean \pm SD or number $(\%)$.

RT, right side of the colon; LT, left side of the colon. 
flexure. Colonic adenoma location was identified as left-sided only, right-sided only, and both right- and left-sided; rightsided adenomas comprised the latter two locations.

The following variables were analyzed for each patient: sex; age; laboratory results; and the number, size, location, and histology results of adenomas found and removed. The results of the fecal occult blood test (FOBT) and body mass index (BMI) were obtained from the medical records. BMI was dichotomized as $\geq 25 \mathrm{~kg} / \mathrm{m}^{2}$ and $<25 \mathrm{~kg} / \mathrm{m}^{2}$ for the analysis. Age was categorized as $<60$ years and $\geq 60$ years.

\section{Statistical analysis}

Characteristics of colonic neoplasia such as the size, location, pathology, and laboratory findings were compared using t-tests for continuous variables and chi-square tests for categorical variables. Continuous variables are presented as the mean \pm standard deviation (SD). We have presented the univariable and multiple regression models that included the relevant variables. For all comparisons, two-sided p-values $<0.05$ were considered statistically significant, and 95\% confidence intervals (CI) are given. The Kaplan-Meier method was used to describe the cumulative incidence of advanced neoplasia. Cox regression analysis was used to determine the hazard ratio (HR) of advanced neoplasia at follow-up colonoscopy according to relevant variables. Analyses were performed using the R Statistical Package version 3.1.2 (Institute for Statistics and Mathematics, Vienna, Austria; http://www.R-project.org) and SAS statistical software version 9.2 (SAS Institute Inc., Cary, NC, USA).

\section{RESULTS}

\section{Characterization of colonic neoplasia at index screening colonoscopy}

The baseline characteristics of the 1,974 subjects are listed in Table 1. At baseline, the subjects' mean age was $55.7 \pm 7.1$ years, and 72.1\% were male. Overall, 1,400 subjects (70.9\%) had colonic adenomas; 572 (29.0\%) had $\geq 2$ colonic adenomas, and 201 (10.2\%) had advanced adenomas. There were 350 (17.7\%), 1,050 (53.2\%), and 574 (29.1\%) subjects in the high-risk, lowrisk, and normal group, respectively. In terms of age, 1,438 subjects (72.8\%) were aged 40 to 59 years; 439 (22.2\%) were aged 60 to 69 years; and 97 (4.9\%) were aged $\geq 70$ years. Right-sided colonic adenomas were seen in 851 of subjects overall (43.1\%), and in $60.8 \%$ of the 1,400 subjects with colonic adenomas. Sixty-nine subjects (3.5\%) had villous histology, 182 (9.2\%) had adenomas $\geq 1 \mathrm{~cm}$ in size, and 239 (12.1\%) had $\geq 3$ adenomas. Of the 1,400 subjects with adenomas, 43 (3.07\%) had serrated adenomas/polyps. In the low-risk group, 17 subjects (1.6\%) had serrated adenomas, whereas 26 subjects (7.4\%) in the high-risk group had serrated adenomas.

\section{Advanced colonic neoplasia at follow-up colonoscopy}

The mean follow-up period was $41.8 \pm 21.7$ months. Overall, 111 subjects were diagnosed with advanced neoplasia (5.6\%)

Table 2. Summary of the Six Patients with Newly Diagnosed Colonic Adenocarcinoma at Follow-up Colonoscopy

\begin{tabular}{|c|c|c|c|c|c|c|c|}
\hline No & Age/sex & $\begin{array}{l}\text { Risk } \\
\text { group }\end{array}$ & $\begin{array}{l}\text { Withdrawal } \\
\text { time, min }\end{array}$ & $\begin{array}{c}\text { Interval, } \\
\text { mo* }^{*}\end{array}$ & $\begin{array}{l}\text { Adenocarcinoma location, size, } \\
\text { type in follow-up colonoscopy }\end{array}$ & TNM stage & Treatment \\
\hline 1 & $68 / \mathrm{M}$ & Low & 8 & 23.9 & $\begin{array}{l}\text { Ascending colon, } 1.2 \mathrm{~cm} \text {, } \\
\text { LST NG type }\end{array}$ & $\begin{array}{l}\text { pT1NOM0 } \\
\text { Adenocarcinoma, well } \\
\text { differentiated }\end{array}$ & $\begin{array}{l}\text { (Laparoscopic) } \\
\text { Right hemicolectomy }\end{array}$ \\
\hline 2 & $58 / \mathrm{M}$ & Low & 8 & 12.0 & $\begin{array}{l}\text { Ascending colon, } 2.5 \mathrm{~cm} \text {, } \\
\text { LST NG type }\end{array}$ & $\begin{array}{l}\text { pTis } \\
\text { Adenocarcinoma, well } \\
\text { differentiated }\end{array}$ & $\begin{array}{l}\text { Endoscopic submucosal } \\
\text { dissection }\end{array}$ \\
\hline 3 & $60 / \mathrm{M}$ & Low & 13 & 35.7 & $\begin{array}{l}\text { Sigmoid colon, } 2.5 \mathrm{~cm} \text {, } \\
\text { ulcerofungating }\end{array}$ & $\begin{array}{l}\text { pT3N1M0 } \\
\text { Adenocarcinoma, moderately } \\
\text { differentiated }\end{array}$ & $\begin{array}{l}\text { (Laparoscopic) } \\
\text { Low anterior resection }\end{array}$ \\
\hline 4 & 73/M & High $^{\dagger}$ & 14 & 29.7 & $\begin{array}{l}\text { Transverse colon, } 1.0 \mathrm{~cm} \text {, } \\
\text { LST NG type }\end{array}$ & $\begin{array}{l}\text { pTis } \\
\text { Adenocarcinoma, well } \\
\text { differentiated }\end{array}$ & $\begin{array}{l}\text { Endoscopic submucosal } \\
\text { dissection }\end{array}$ \\
\hline 5 & $57 / \mathrm{M}$ & High & 15 & 68.8 & $\begin{array}{l}\text { Ascending colon, } 3.0 \mathrm{~cm} \text {, } \\
\text { ulcero-infiltrative }\end{array}$ & $\begin{array}{l}\text { pT3N2aM1 } \\
\text { Mucinous adenocarcinoma }\end{array}$ & $\begin{array}{l}\text { Extended right hemicolectomy } \\
\text { Right adrenalectomy }\end{array}$ \\
\hline 6 & 70/M & Normal & $<6$ & 54.2 & $\begin{array}{l}\text { Transverse colon, } 1.0 \mathrm{~cm} \text {, } \\
\text { ulcerative }\end{array}$ & $\begin{array}{l}\text { pT1NOM0 } \\
\text { Adenocarcinoma, well } \\
\text { differentiated }\end{array}$ & $\begin{array}{l}\text { (Laparoscopic) } \\
\text { Transverse colectomy }\end{array}$ \\
\hline
\end{tabular}

TNM stage, depth of invasion: submucosa (pT1), subserosa (pT3), adenocarcinoma in situ (pTis).

M, male; LST NG, laterally spreading tumor, nongranular.

*Months between the index screening colonoscopy and follow-up colonoscopy at which cancer was detected; ${ }^{\dagger}$ Polypectomy in the index colonoscopy with pathology-proven complete resection of the adenoma. 
during follow-up colonoscopy (after having undergone complete screening and removal of all polyps at the index colonoscopy). Of these, 58 subjects (52.3\%) had $\geq 3$ adenomas, 96 (86.5\%) had lesions $\geq 1 \mathrm{~cm}$ in size, and 23 adenomas (20.7\%) had villous histology. No significant difference in the location of these advanced neoplasms was observed between the right- $(n=69$, $62.2 \%)$ and left-sided $(n=42,37.8 \%)$ colon $(p=0.219)$.

Six subjects were newly diagnosed with adenocarcinomas during follow-up colonoscopy (Table 2): one from the normal group, three from the low-risk group, and two from the highrisk group. All six adenocarcinomas were located in different sites from where adenomas were removed at the index colonoscopy; five were located in the right-sided colon (one in the sigmoid colon, two in the transverse colon, and three in the ascending colon). Two cases were treated with endoscopic submucosal dissection (both had adenocarcinoma in situ [pTis]); the others were treated surgically (two cases had submucosal [pT1] invasion and two cases had subserosal [pT3] invasion). One subject had metastases to the adrenal gland. After adjuvant chemotherapy, an extended right hemicolectomy with right adrenalectomy was performed. The final pathology was mucinous adenocarcinoma with serosal invasion.

\section{Cumulative incidence of advanced neoplasia at follow-up colonoscopy}

Incidence of advanced neoplasia at the follow-up colonoscopy according to risk group are listed in Table 3. The 3-year cumulative incidences of advanced neoplasia stratified by risk group were as follows: high-risk group, 10.2\% (95\% CI, 0.86 to 0.94 ); low-risk group $3.1 \%$ (95\% CI, 0.96 to 0.98 ); normal group $0.8 \%$ (95\% CI, 0.98 to 1.00$)(\mathrm{p}<0.0001)$. The corresponding 5-year cumulative incidences of advanced neoplasia were 20.2\% (95\% CI, 0.74 to 0.87 ); 8.6\% (95\% CI, 0.89 to 0.94); and $2.2 \%$ (95\% CI, 0.96 to 0.99), respectively ( $<<0.0001$ ) (Fig. 1). The 3-year cumulative incidence of advanced neoplasia stratified by age group was 40 to 59 years, 2.6\% (95\% CI, 0.96 to 0.98); 60 to 69 years, $4.6 \%$ (95\% CI, 0.93 to 0.98 ); and $\geq 70$ years, $10.0 \%$ (95\% CI, 0.84 to 0.97$)(\mathrm{p}<0.0001)$. The corresponding 5-year cumulative incidences were $6.7 \%$ (95\% CI, 0.91 to 0.95); $10.0 \%$ (95\% CI, 0.86 to 0.94); and 19.4\% (95\% CI, 0.70 to 0.92), respectively $(\mathrm{p}<0.0001)$. Age $\geq 60$ years, current smoking, FOBT posi- tivity, right-sided colonic adenoma at index colonoscopy, lowrisk group (vs normal), high-risk group (vs normal) and highrisk components ( $\geq 3$ adenomas, adenoma $\geq 1 \mathrm{~cm}$ in size, villous type) were risk factors for subsequent advanced neoplasia in the univariable analysis.

In the multivariable analysis, age $\geq 60$ years (vs $<60$ years: HR, 1.78; 95\% CI, 1.21 to 2.63), right-sided colonic adenomas (vs non-right-sided colonic adenomas: HR, 1.74; 95\% CI, 1.13 to 2.66), $\geq 3$ adenomas (vs no adenomas $\geq 3$ : HR, 2.00; 95\% CI, 1.22 to 3.28), and adenoma $\geq 1 \mathrm{~cm}$ in size (vs no adenoma $\geq 1 \mathrm{~cm}$ : $\mathrm{HR}, 2.03$; 95\% CI, 1.20 to 3.44) at index colonoscopy were independent risk factors for recurrent advanced neoplasia at followup (Table 4).

\section{DISCUSSION}

The incidence of CRC in Korea is increasing. The annual percentage change in age-standardized incidence rates between

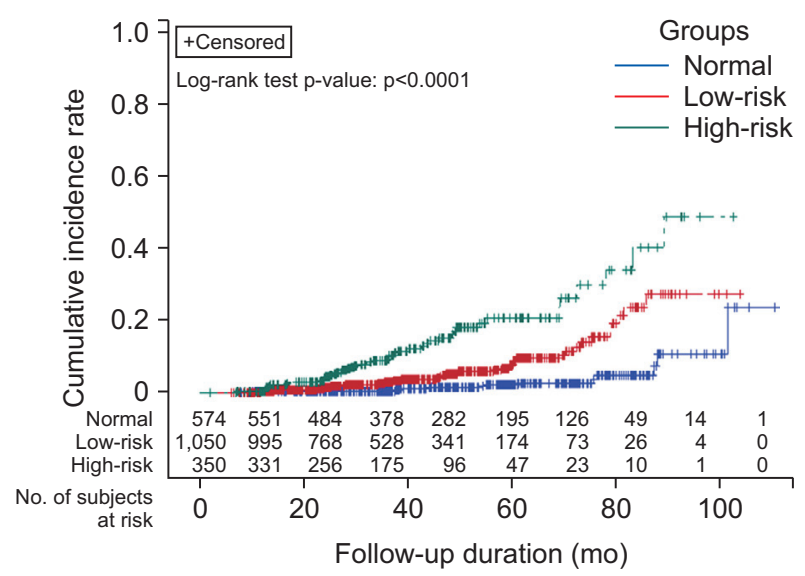

Fig. 1. Cumulative incidence of recurrent advanced neoplasia according to risk group at the index colonoscopy. The 3-year cumulative incidence of advanced neoplasia in each risk group was 10.2\% in the high-risk group (advanced neoplasia or $\geq 3$ adenomas; 95\% confidence interval [CI], 0.86-0.94), 3.1\% in the low-risk group (1-2 adenomas $<1 \mathrm{~cm}$ in size; $95 \% \mathrm{CI}, 0.96-0.98)$, and $0.8 \%$ in the normal group (95\% CI, 0.98-1.00) ( $\mathrm{p}<0.0001)$. The 5 -year cumulative incidence of advanced neoplasia in each risk group was $20.2 \%$ in the high-risk group (95\% CI, 0.74-0.87), 8.6\% in the low-risk group (95\% CI, 0.89-0.94), and 2.2\% in the normal group (95\% CI, 0.96-0.99) $(\mathrm{p}<0.0001)$.

Table 3. Incidence of Advanced Neoplasia at Follow-up Colonoscopy According to Risk Group ( $\mathrm{p}<0.0001)$

\begin{tabular}{|c|c|c|c|c|c|c|c|c|c|}
\hline \multirow{2}{*}{$\begin{array}{l}\text { Follow-up } \\
\text { duration, mo }\end{array}$} & \multicolumn{3}{|c|}{ Normal group $(\mathrm{n}=574)$} & \multicolumn{3}{|c|}{ Low-risk group $(\mathrm{n}=1,050)$} & \multicolumn{3}{|c|}{ High-risk group $(\mathrm{n}=350)$} \\
\hline & $\begin{array}{l}\text { No. } \\
\text { risk }\end{array}$ & $\begin{array}{c}\text { Cumulative } \\
\text { incidence rate (\%) }\end{array}$ & $95 \% \mathrm{CI}$ & $\begin{array}{l}\text { No. } \\
\text { risk }\end{array}$ & $\begin{array}{c}\text { Cumulative } \\
\text { incidence rate (\%) }\end{array}$ & $95 \% \mathrm{CI}$ & $\begin{array}{l}\text { No. } \\
\text { risk }\end{array}$ & $\begin{array}{c}\text { Cumulative } \\
\text { incidence rate (\%) }\end{array}$ & $95 \% \mathrm{CI}$ \\
\hline 36 & 367 & 0.8 & $0.984-1.000$ & 543 & 3.1 & $0.957-0.982$ & 179 & 10.2 & $0.861-0.936$ \\
\hline 48 & 322 & 1.4 & $0.975-0.997$ & 374 & 5.2 & $0.930-0.967$ & 102 & 15.7 & $0.793-0.895$ \\
\hline 60 & 238 & 2.2 & $0.962-0.994$ & 187 & 8.6 & $0.885-0.944$ & 61 & 20.2 & $0.736-0.866$ \\
\hline 72 & 188 & 2.7 & $0.954-0.992$ & 80 & 12.2 & $0.834-0.925$ & 23 & 28.7 & $0.612-0.830$ \\
\hline
\end{tabular}

No. risk, numbers of subjects at risk; CI, confidence interval. 
Table 4. Relative Risks of Advanced Neoplasia at the Follow-up Colonoscopy According to the Characteristics at the Index Colonoscopy

\begin{tabular}{|c|c|c|c|c|}
\hline \multirow{2}{*}{ Characteristic } & \multicolumn{2}{|c|}{ Univariable analysis } & \multicolumn{2}{|c|}{ Multivariable analysis } \\
\hline & $\mathrm{HR}(95 \% \mathrm{CI})$ & p-value & $\operatorname{HR}(95 \% \mathrm{CI})$ & p-value \\
\hline \multicolumn{5}{|l|}{ Age, yr } \\
\hline$<60$ & 1 & & 1 & \\
\hline$\geq 60$ & $2.090(1.4436-3.043)$ & 0.0001 & $1.781(1.208-2.625)$ & 0.004 \\
\hline \multicolumn{5}{|l|}{ Sex } \\
\hline Female & 1 & & 1 & \\
\hline Male & $1.156(0.744-1.794)$ & 0.519 & $0.854(0.536-1.359)$ & 0.505 \\
\hline \multicolumn{5}{|l|}{ Family history of colorectal cancer } \\
\hline No & 1 & & 1 & \\
\hline Yes & $1.356(0.553-3.325)$ & 0.506 & $1.521(0.610-3.796)$ & 0.369 \\
\hline \multicolumn{5}{|l|}{ Current smoking } \\
\hline No & 1 & & 1 & \\
\hline Yes & $1.592(1.019-2.486)$ & 0.041 & $1.451(0.897-2.347)$ & 0.129 \\
\hline \multicolumn{5}{|l|}{$\mathrm{BMI} \geq 25 \mathrm{~kg} / \mathrm{m}^{2}$} \\
\hline No & 1 & & 1 & \\
\hline Yes & $1.101(0.745-1.626)$ & 0.629 & $1.082(0.728-1.608)$ & 0.698 \\
\hline \multicolumn{5}{|l|}{ Stool occult blood test positivity } \\
\hline No & 1 & & 1 & \\
\hline Yes & $2.040(1.094-3.806)$ & 0.025 & $1.205(0.610-2.381)$ & 0.591 \\
\hline \multicolumn{5}{|c|}{ Right-sided colonic adenoma at index colonoscopy } \\
\hline No & 1 & & 1 & \\
\hline Yes & $2.646(1.803-3.883)$ & $<0.0001$ & $1.736(1.131-2.664)$ & 0.012 \\
\hline \multicolumn{5}{|l|}{ Risk groups } \\
\hline Normal & 1 & & & \\
\hline Low-risk & $3.391(1.867-6.161)$ & $<0.0001$ & & \\
\hline High risk & $9.103(4.966-16.686)$ & $<0.0001$ & & \\
\hline \multicolumn{5}{|l|}{ High-risk component } \\
\hline$\geq 3$ Adenomas (vs no adenomas $\geq 3$ ) & $3.880(2.576-5.844)$ & $<0.0001$ & $2.000(1.218-3.282)$ & 0.006 \\
\hline Adenoma $\geq 1 \mathrm{~cm}$ (vs no adenoma $\geq 1 \mathrm{~cm}$ ) & $3.814(2.469-5.891)$ & $<0.0001$ & $2.034(1.204-3.436)$ & 0.008 \\
\hline Villous type (vs no villous adenoma) & $3.730(1.999-6.961)$ & $<0.0001$ & $1.130(0.544-2.348)$ & 0.743 \\
\hline
\end{tabular}

HR, hazard ratio; CI, confidence interval; BMI, body mass index.

1999 and 2009 was $+6.2 \% .^{3}$ The age-standardized mortality rates of CRC continue to increase, unlike those of other common cancers whose mortality rates have decreased in recent years. ${ }^{13}$ The prevalence of colorectal neoplasms in Korean individuals aged 50 to 59 years was 30.1\% for overall neoplasia and 6.7\% for advanced neoplasia. ${ }^{14}$ In this study, the proportion of subjects with adenomas increased significantly with age. Notably, a previous study reported that increasing age was associated with a higher prevalence of right-sided lesions. ${ }^{14}$

According to the Korean guidelines for postpolypectomy colonoscopic surveillance, patients should be considered at high risk for subsequent advanced neoplasia at surveillance colonoscopy when one or more of the following conditions have been detected at index colonoscopy: (1) 3 or more adenomas, (2) any adenoma larger than $10 \mathrm{~mm}$, (3) any tubulovillous or villous adenoma, (4) any adenoma with high-grade dysplasia, and (5) any serrated polyps larger than $10 \mathrm{~mm} .{ }^{15}$ Adenomas located in the right side of the colon at index colonoscopy are of concern but not confirmed.

Two recent retrospective studies reported that age was a significant risk factor for developing colorectal neoplasms after removal of high-risk adenomas, ${ }^{10}$ and that the presence of multiple high-risk findings was associated with an increased risk of advanced neoplasia during surveillance. ${ }^{11}$ Concurring with the findings of a retrospective study conducted by the Intestinal Cancer Study Group of the Korean Association for the Study of Intestinal Diseases, ${ }^{10}$ we also found that in the multivariate analysis, age $\geq 60$ years was a significant risk factor for ad- 
vanced colorectal neoplasia following complete screening colonoscopy with removal of all polyps.

Chung et al. ${ }^{9}$ reported in a prospective study that the 5-year and 3-year incidence of advanced adenoma among high-risk patients was $12.2 \%$ and 9.6\%, respectively, after adenoma removal. In the present study, the 5-year and 3-year incidence of advanced neoplasia at follow-up colonoscopy in the high-risk group was $20.2 \%$ and $10.2 \%$, respectively. Follow-up colonoscopy at 3 years is recommended for patients with any of the following: $\geq 3$ adenomas, a tubular adenoma $\geq 1 \mathrm{~cm}$ in size, a villous adenoma $\geq 1 \mathrm{~cm}$ in size, and an adenoma with highgrade dysplasia. ${ }^{16}$ In the Asia Pacific Consensus, a risk-stratified scoring system is recommended for selecting factors indicating high-risk for CRC and advanced neoplasia. ${ }^{17}$ The scoring system includes age (50 to 69 years vs $\geq 70$ years), male sex, having a first-degree relative with CRC, and current or past smoking. ${ }^{17}$ Low-risk is defined as having 0 to 1 criterion; intermediate-risk, 2 to 3 criteria; and high-risk, 4 to 7 criteria. ${ }^{17}$ In this study, after adjustment for age, sex, family history of CRC, smoking, BMI $>25 \mathrm{~kg} / \mathrm{m}^{2}$, FOBT positivity, $\geq 3$ adenomas, adenoma $\geq 1 \mathrm{~cm}$ in size, villous component, and adenoma location, the following factors at index colonoscopy were significant risk factors for advanced neoplasia at follow-up colonoscopy: age $\geq 60$ years, $\geq 3$ adenomas, adenoma $\geq 1 \mathrm{~cm}$ in size, and any right-sided colonic adenoma. Although the presence of right-sided colonic adenomas at index colonoscopy was not considered as a high risk condition for subsequent advanced neoplasia at surveillance colonoscopy, the trend toward a greater number of adenomas missed in the right-side colon compared with the left was of concern. $^{18}$

In the subanalysis, right-sided only colonic adenomas were significant in the multivariable analysis (Supplementary Table 1). Age $\geq 60$ years, right-sided only colonic adenoma, $\geq 3$ adenomas, and adenoma $\geq 1 \mathrm{~cm}$ in size were also significant risk factors for advanced adenoma at follow-up colonoscopy. Hence, we presented that any right-sided colonic adenoma is significant for subsequent advanced neoplasia. However, no significant difference in the location of subsequent advanced neoplasia was observed between the right- (62.2\%) and left-sided colon (37.8\%) $(\mathrm{p}=0.219)$. At index colonoscopy, right-sided only adenoma was seen in $45.2 \%$ of subjects in the low-risk group and in 19.1\% of subjects in the high-risk group, while both right- and left-sided adenomas were seen in $10.4 \%$ and $57.2 \%$ of subjects in the low-risk and high-risk group, respectively. This difference at index colonoscopy could affect the outcome. Otherwise, bacterial biofilms are associated with CRC and microbiota organization is a distinct feature of proximal CRCs; ${ }^{19}$ the location of baseline adenomas could be a risk factor for advanced colonic neoplasia, but further studies are needed.

There were six (male) subjects who had adenocarcinomas diagnosed at follow-up colonoscopy. These adenocarcinomas were located in the right-sided colon in five of the six subjects
(83\%).

There are several possible reasons for these six subsequent colonic cancers detected at follow-up colonoscopy. First, it is possible that lesions were missed at the index colonoscopy. Rightsided sessile serrated adenomas or spreading-type advanced lesions are easy to miss. In these six patients, ulcerative type $(n=1)$, ulcero-infiltrative type $(n=1)$, ulcero-fungating type $(n=1)$, and laterally spreading tumor nongranular type $(n=3)$ was tumors were seen, these lesions could have been missed at index colonoscopy. Second, incomplete resection of a lesion is possible. At index colonoscopy, four cases were treated with biopsy removal and one with polypectomy. Even though complete resection was reported in the polypectomy case, a remnant lesion at the biopsy site could be the reason for interval cancer. Third, new lesions or rapid progression is possible. A CIMP (CpG island methylator phenotype)-high/BRAF (B-type Raf kinase) mutation or microsatellite instability could result in rapid progression of cancer after dysplasia, or a sessile-serrated adenoma/polyp could be a precursor of interval cancer. Sessile-serrated adenomas/polyps are more prevalent in the right-sided colon. Moreover, 83\% of follow-up colon cancers were right-sided in this study. Last, inappropriate withdrawal time at index colonoscopy is a possible reason for interval cancer. The withdrawal time of 618 index colonoscopies (31.3\%) was $<6$ minutes (colonoscopy procedure time: $\operatorname{mean}_{ \pm} \mathrm{SD}, 13.5 \pm 6.2$ minutes; withdrawal time: mean \pm SD, $7.9 \pm 5.0$ minutes). A withdrawal time of $<6$ minutes was mostly noted from 2007 to 2009 (85.9\%).

The current study had several limitations. It was retrospective and conducted at a single center; it was not population based. It included individuals who underwent regular health examinations, which could have introduced selection bias and the potential for incomplete data. Follow-up duration also varied. We could not measure other confounders, such as food intake and consumption. Those who underwent screening were funded by employers (60\%) or were self-funded (40\%), and may have been more health conscious than the general population. ${ }^{20}$ The incidence of lesions, chance of missed lesions, or incomplete removal at initial screening colonoscopy was possible. ${ }^{21}$ The Boston Bowel Preparation Scale was applied for assessment of the quality of bowel preparation in 2011; prior to that, data were subjectively categorized by the endoscopist as "excellent," "good," "fair," and "poor." Although subjects with "excellent," "good" and "fair" bowel preparation were analyzed, these terms lacked standardized definitions. Nevertheless, considering the emerging interest in interval colon cancer in patients, advanced neoplasia at follow-up colonoscopy according to risk group, risk components and baseline adenoma location was useful in furthering the understanding of advanced neoplasia in the average-risk individual.

In conclusion, the 3-year cumulative incidence of advanced neoplasia by risk group was 10.2\%, 3.1\%, and 0.8\% in the highrisk, low-risk, and normal group, respectively. The correspond- 
ing 5-year cumulative incidences were $20.2 \%$, $8.6 \%$, and $2.2 \%$, respectively. In terms of high-risk components, $\geq 3$ adenomas, adenomas $\geq 1 \mathrm{~cm}$, any right-sided colonic adenoma, and age $\geq 60$ years at index colonoscopy were significant risk factors for advanced neoplasia at follow-up colonoscopy. Further studies are needed for adenoma location, especially right-sided colonic location, and subsequent advanced neoplasia.

\section{CONFLICTS OF INTEREST}

No potential conflict of interest relevant to this article was reported.

\section{REFERENCES}

1. American Cancer Society. Cancer facts and figures 2008 [Internet]. Atlanta: American Cancer Society; 2008 [cited 2014 Mar 16]. Available from: http://www.cancer.org/research/cancerfactsstatistics/index.

2. Boyle P, Ferlay J. Cancer incidence and mortality in Europe, 2004. Ann Oncol 2005;16:481-488.

3. Jung KW, Won YJ, Kong HJ, et al. Cancer statistics in Korea: incidence, mortality, survival, and prevalence in 2012. Cancer Res Treat 2015;47:127-141.

4. Jung KW, Park S, Kong HJ, et al. Cancer statistics in Korea: incidence, mortality, survival, and prevalence in 2009. Cancer Res Treat 2012;44:11-24.

5. Winawer SJ, Fletcher RH, Miller L, et al. Colorectal cancer screening: clinical guidelines and rationale. Gastroenterology 1997;112:594642.

6. Winawer SJ, Zauber AG, Ho MN, et al. Prevention of colorectal cancer by colonoscopic polypectomy. N Engl J Med 1993;329:19771981.

7. Baxter NN, Goldwasser MA, Paszat LF, Saskin R, Urbach DR, Rabeneck L. Association of colonoscopy and death from colorectal cancer. Ann Intern Med 2009;150:1-8.

8. Rex DK, Petrini JL, Baron TH, et al. Quality indicators for colonoscopy. Am J Gastroenterol 2006;101:873-885.

9. Chung SJ, Kim YS, Yang SY, et al. Five-year risk for advanced colorectal neoplasia after initial colonoscopy according to the baseline risk stratification: a prospective study in 2452 asymptomatic Koreans. Gut 2011;60:1537-1543.

10. Park SK, Kim NH, Jung YS, et al. Risk of developing advanced colorectal neoplasia after removing high-risk adenoma detected at index colonoscopy in young patients: a KASID study. J Gastroenterol Hepatol 2016;31:138-144.

11. Lee SM, Kim JH, Sung IK, Hong SN. The risk of metachronous advanced colorectal neoplasia rises in parallel with an increasing number of high-risk findings at baseline. Gut Liver 2015;9:741749.

12. Lieberman DA, Weiss DG, Bond JH, et al. Use of colonoscopy to screen asymptomatic adults for colorectal cancer. N Engl J Med 2000;343:162-168.

13. Lee BI, Hong SP, Kim SE, et al. Korean guidelines for colorectal cancer screening and polyp detection. Clin Endosc 2012;45:25-43.

14. Boursi B, Halak A, Umansky M, Galzan L, Guzner-Gur H, Arber N. Colonoscopic screening of an average-risk population for colorectal neoplasia. Endoscopy 2009;41:516-521.

15. Yang DH, Hong SN, Kim YH, et al. Korean guidelines for postpolypectomy colonoscopy surveillance. Clin Endosc 2012;45:44-61.

16. Strum WB. Colorectal adenomas. N Engl J Med 2016;374:10651075.

17. Sung JJ, Ng SC, Chan FK, et al. An updated Asia Pacific consensus recommendations on colorectal cancer screening. Gut 2015;64:121-132.

18. Hewett DG, Rex DK. Miss rate of right-sided colon examination during colonoscopy defined by retroflexion: an observational study. Gastrointest Endosc 2011;74:246-252.

19. Dejea CM, Wick EC, Hechenbleikner EM, et al. Microbiota organization is a distinct feature of proximal colorectal cancers. Proc Natl Acad Sci U S A 2014;111:18321-18326.

20. Yang MH, Rampal S, Sung J, et al. The prevalence of colorectal adenomas in asymptomatic Korean men and women. Cancer Epidemiol Biomarkers Prev 2014;23:499-507.

21. Lieberman DA, Weiss DG, Harford WV, et al. Five-year colon surveillance after screening colonoscopy. Gastroenterology 2007;133:10771085. 